\title{
Estudo anatômico da inervação do músculo supinador para reinervar o nervo interósseo posterior*
}

\section{Anatomical Study of Innervation of the Supinator Muscle to Reinnervate the Posterior Interosseous Nerve}

\author{
Edie Benedito Caetano ${ }^{10}$ Luiz Angelo Vieira ${ }^{1}$ João José Sabongi Neto ${ }^{2}$ Maurício Ferreira Caetano ${ }^{2}$ \\ Rodrigo Guerra Sabongi ${ }^{3}$ Bruno Azi Pacileo Cruz ${ }^{1}$
}

1 Faculdade de Ciências Médicas e da Saúde, Pontifícia Universidade Católica de São Paulo, Sorocaba, SP, Brasil

${ }^{2}$ Serviço de Cirurgia da Mão, Conjunto Hospitalar de Sorocaba (CHS),

Address for correspondence Edie Benedito Caetano, PhD, Rua Joubert Wey, 290, CEP: 18030-070, Sorocaba, SP, Brasil

Sorocaba, SP, Brasil

${ }^{3}$ Residência Médica em Ortopedia, Universidade Federal do Estado de

São Paulo (UNIFESP), São Paulo, SP, Brasil

(e-mail: ediecaetano@uol.com.br).

Rev Bras Ortop 2019;54:253-260.

\begin{abstract}
Resumo
Palavras-chave

- plexo braquial

- músculo esquelético

- nervos periféricos

- dedos

- transferência de nervo

Objetivo O objetivo deste estudo anatômico, foi analisar a possibilidade de transferir os ramos do nervo radial destinados ao músculo supinador para reinervar o nervo interósseo posterior (NIP), que se origina das raízes C7-T1.

Métodos Foram dissecados 30 membros de 15 cadáveres, todos do sexo masculino, preparados por injeção intra-arterial de uma solução de glicerina e formol a $10 \%$.

Resultados Em todos os membros dissecados, encontramos pelo menos um ramo destinado a cada uma das cabeças - superficial e profunda - do músculo supinador. Esses tiveram origem no NIP. Identificamos, proximal à arcada de Frohse, um ramo para o supinador em seis membros; 2 ramos para o supinador em 11 membros e 3 ramos em 4 membros. Em dois membros, apenas um ramo desprendia-se do NIP, mas se duplicava proximalmente à arcada de Frohse. Em sete membros, não identificamos ramos para o supinador proximal à arcada de Frohse. Os ramos destinados ao músculo supinador foram seccionados na junção neuromuscular, podendo ser conectados sem tensão ao NIP. O diâmetro somado dos ramos destinados ao músculo supinador correspondeu, em média, a 53,5\% do diâmetro do NIP.

Conclusão Este estudo anatômico mostra que ramos do nervo radial destinados ao músculo supinador podem ser transferidos diretamente para o NIP sem tensão para restaurar a extensão do polegar e dos dedos em pacientes com lesões de plexo braquial C7-T1.
\end{abstract}

Trabalho realizado na Pontifícia Universidade Católica de São Paulo, Faculdade de Ciências Médicas e da Saúde, Sorocaba, SP, Brasil.

(D) Edie Benedito Caetano's ORCID is https://orcid.org/0000-0003-45723854.

received

February 20, 2018

accepted

May 15, 2018
DOI https://doi.org/

10.1055/s-0039-1692459.

ISSN 0102-3616.
Copyright $\odot 2019$ by Sociedade Brasileira License terms de Ortopedia e Traumatologia. Published by Thieme Revnter Publicações Ltda, Rio de Janeiro, Brazil 


\begin{abstract}

\section{Keywords}

- brachial plexus

- skeletal muscle

- peripheral nerves

- fingers

- nerve transfer

Objective The purpose of this anatomical study was to analyze the possibility of transferring the branches of the radial nerve to the supinator muscle to reinnervate the posterior interosseous nerve (PIN), originating from the C7-T1 roots.

Methods A total of 30 members of 15 cadavers were dissected. They were all male and were prepared by intra-arterial injection of a solution of glycerol and formaldehyde. Results In all dissected limbs, we found at least one branch intended for each of the superficial and deep heads of the supinator muscle. These originated from the PIN. We identified, proximal to the Frohse arcade, 1 branch to the supinator in 6 members; two branches to the supinator in 11 members, and 3 branches in 4 members. In two limbs, only one branch was detached from the PIN, but it duplicated proximal to the Frohse arcade. In seven limbs, we did not identify branches to the supinator proximal to the arcade of Frohse. The branches destined for the supinator muscle were sectioned at the neuro muscular junction and could be connected without tension to the PIN. The combined diameter of the branches for the supinator muscle corresponded, on average, to $53.5 \%$ of the PIN.

Conclusion The radial nerve branches intended for the supinator muscle can be transferred, tension free, directly to the PIN to restore thumb and finger extension in patients with C7-T1 brachial plexus lesions.
\end{abstract}

\section{Introdução}

A reparação de uma lesão nervosa baseia-se na reparação primária do nervo, enxertos de nervos, transferências tendinosas e transferência livre de músculos. No entanto, existem lesões nervosas que não são passíveis de reparação primária e para as quais os enxertos não proporcionam resultados satisfatórios, e as transferências tendinosas podem estar limitadas pela disponibilidade de músculos doadores. Estas lesões incluem lesão do nervo muito proximal; zona de lesão extensa, resultando em um longo espaço entre os cotos nervosos, e paralisia idiopática do nervo ou neurite, em que não existe segmento nervoso

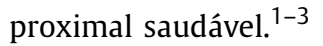

No caso das lesões do plexo braquial com intervalos muito grandes entre as extremidades nervosas, pode não haver tempo suficiente para regenerar os axônios para atingir as placas motoras terminais dos músculos alvos antes de se tornarem permanentemente resistentes à reinervação. Este período prolongado de denervação deixa os músculos suscetíveis a degeneração irreversível e fibrose das placas motoras terminais. Para esses problemas, a transferência de nervos oferece uma opção cirúrgica possível. ${ }^{1,4,5}$ As lesões das raízes $\mathrm{C} 7$ ou $\mathrm{C} 8$ e $\mathrm{T} 1$ resultam em disfunção dos músculos intrínsecos da mão, dos flexores do punho e dos flexores e extensores do polegar. A recuperação funcional da mão paralisada, é um grande desafio para todos que enfrentam esse tipo de lesão.

O nervo radial inerva todos os músculos do compartimento posterior do braço e do antebraçoe passa do compartimento posterior para o anterior contornando o sulco do nervo radial no úmero. $O$ nervo radial passa ainda pelo septo intermuscular, entre os músculos braquial (MB) medialmente e braquiorradial (BR) lateralmente e continua infe- riormente no compartimento anterior do braço. Mais distalmente, ele emerge entre os músculos BR e extensor radial longo do carpo (ERLC), a partir de onde divide-se em ramo superficial do nervo radial (RSNR) e nervo interósseo posterior (NIP), também chamado ramo profundo do nervo radial (RPNR). O túnel radial é uma estrutura músculoaponeurótica que se estende desde o epicôndilo lateral do úmero até a borda distal do músculo supinador (MS) ${ }^{6,7} \mathrm{O}$ MS é composto por duas cabeças, superficial e profunda, o NIP posiciona-se entre elas. A borda proximal da cabeça superficial do MS pode formar uma arcada fibrosa de espessura e comprimento variável também conhecida como arcada de Frohse (AF), descrita em 1908 por Frohse e Frankel, ${ }^{8}$ que é relatada como o local mais comum de compressão do NIP. ${ }^{7,9,10}$ Estudos eletrofisiológicos comprovaram que a inervação do MS se origina das raízes C5 C6, e a inervação do NIP das raízes C7-T1. ${ }^{11-13}$ Os ramos destinados ao MS ficam próximos do nervo interósseo posterior e a transferência direta pode ser realizada facilmente, o que facilita e acelera a reinervação. A supinação do antebraço é realizada por dois músculos principais, o bíceps braquial e o supinador, e ambos estão preservados nas paralisias C7-T1.$^{14}$ Portanto, o sacrifício dos ramos motores do supinador não compromete a supinação devido à compensação do bíceps. As vantagens do uso de nervos doadores distais incluem a proximidade das placas motoras terminais, atuar numa área de estruturas anatômica não comprometida por tecido fibroso, e garantir uma fonte de axônios motores viáveis oriundos do nervo doador. ${ }^{15}$

A finalidade deste trabalho foi realizar em 30 membros de cadáveres o estudo anatômico dos ramos do nervo radial direcionados ao MS e ao nervo interósseo posterior com suas ramificações e avaliar anatomicamente alguns detalhes dessa transferência nervosa. 


\section{Material e Métodos}

Este estudo baseou-se na dissecção de 30 membros superiores de 15 cadáveres, todos do sexo masculino. Os cadáveres foram preparados por injeção intra-arterial de uma solução de glicerina e formol a $10 \%$. Cada antebraço foi dissecado, com o cotovelo em extensão, o punho em posição neutra e o antebraço em pronação. Nenhum dos cadáveres apresentou evidências de deformidades, procedimentos cirúrgicos anteriores ou lesões traumáticas na área estudada. Removemos a pele e a fáscia da superfície flexora e extensora do terço distal do braço, do antebraço e do punho. O nervo radial foi identificado no braço entre os músculos braquial e braquiorradial e dissecado de proximal para distal. Os tendões dos músculos BR, ERLC e extensor radial curto do carpo (ERCC) foram seccionados em seu terço distal, separados das conexões fibrosas que os unia para facilitar a identificação dos ramos nervosos.

Os ramos destinados aos músculos BR, ERLC, ERCC, MS e NIP foram dissecados. As estruturas vasculares não foram preservadas para facilitar a dissecção dos nervos. Utilizamos, em certas fases da dissecção, uma lupa de 2,5 vezes de aumento. A ordem de inervação de cada músculo e o número de ramos foram registrados. O nervo interósseo posterior foi identificado nas margens proximal e distal do MS e dissecado ao longo de seu trajeto entre as cabeças superficial e profunda do MS, expondo dessa forma todos os seus ramos. Identificamos o número de ramos proximal à $\mathrm{AF}$ e no interior da massa muscular do supinador. O nervo interósseo posterior foi seguido distalmente até sua entrada nos músculos do antebraço. Um paquímetro digital foi usado para medir o diâmetro dos nervos. A medida do diâmetro do NIP, foi realizada distal a ramificação para o MS. A medida do diâmetro dos ramos para o MS foi medida $0,5 \mathrm{~cm}$ distal a sua origem no NIP (-Figs. 1A e 1B). Os ramos destinados ao MS foram seccionados junto a junção neuromuscular e facilmente conectados ao NIP, simulando dessa forma 0 procedimento cirúrgico no membro cadavérico.

\section{Resultados}

Para facilitar o entendimento das figuras, do que é proximal ou distal, colocamos as letras A e B, sempre do lado proximal das figuras. Em todos os membros dissecados encontramos pelo menos um ramo destinado a cada uma das cabeças superficial e profunda do MS. Esses tiveram origem no NIP. Identificamos, proximal à AF, 1 ramo para o MS em 6 membros (-Figs. 2A e 2B), 2 ramos para o MS em 11 membros (-Fig. 3A) e 3 ramos em 4 membros (-Fig. 3B). Em dois membros, apenas um ramo desprendia-se do NIP, mas se duplicava proximalmente á AF (-Fig. 4A). Em sete membros, não identificamos ramos para o $\mathrm{MS}$ proximal à $\mathrm{AF}$ (-Fig. 4B). Em todos os membros, identificamos as cabeças superficial e profunda do MS (-Figs. 5A e 5B). A cabeça superficial recebeu apenas 1 ramo em 19 membros (-Fig. 5A) e 2 ramos em 11 (-Fig. 5B). A cabeça profunda recebeu 1 ramo em 18 membros (-Fig. 5A), 2 ramos em 10 (-Fig. 6A) e 3 ramos em 2 membros (-Fig. 6B). O NIP

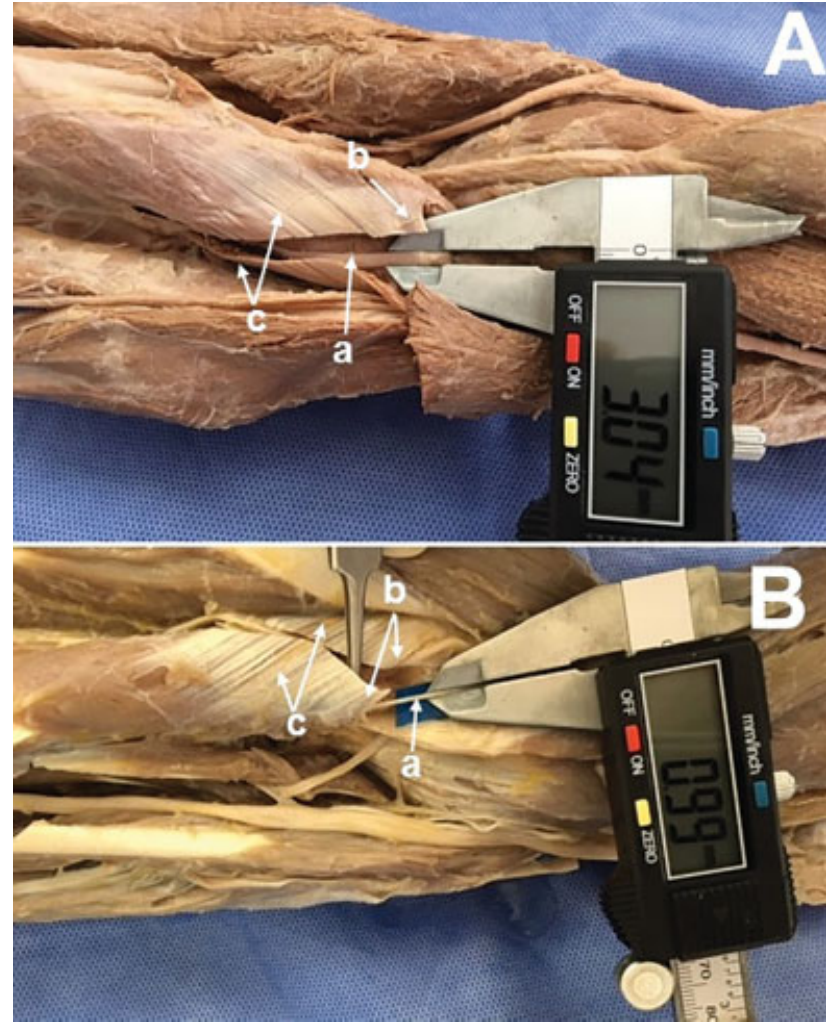

Fig. 1A Medida do diâmetro do nervo interósseo posterior, distal a ramificação para o músculo supinador. Nervo interósseo posterior (a); arcada de Frohse (b); músculo supinador (c). 1B - Medida do diâmetro de um ramo para o músculo supinador, $0,5 \mathrm{~cm}$ distal a sua origem no nervo interósseo posterior. Nervo interósseo posterior (a); arcada de Frohse (b); músculo supinador (c).

emergiu na margem distal do MS em 26 membros ( - Fig. 7A). Em quatro membros, emergia perfurando o corpo MS (-Fig. 7B). Os ramos terminais do NIP direcionavam-se distalmente para inervar os músculos do antebraço. Em 25 membros, observamos que sua ramificação, distal do NIP em ramos superficial e profundo, ocorreu ao nível ou inferiormente a margem distal do MS (- Fig. 8A); em cinco membros, a divisão ocorreu na substância do MS (-Fig. 8B). O diâmetro médio do NIP, distal ao desprendimento dos ramos e proximal à sua ramificação distal, foi de $3,0+-0,5$, e a soma do diâmetro médio dos ramos endereçados ao MS somada foi de 1,4+-0,8 mm (-Figs. 9A e 9B). Seccionando os ramos para as cabeças superficial e profunda do supinador, no ponto de penetração no músculo, e observamos que as extremidades desses nervos poderiam ser conectadas ao NIP sem tensão (no detalhe -Figs. 5B, 9A e 9B).

\section{Discussão}

Neste estudo, identificamos que a divisão do nervo radial em NIP e RSNR ocorreu proximalmente à linha intercondilar do úmero (LIU) em todos os membros. Os ramos do nervo radial para o BR e ERLC se desprenderam do nervo radial proximalmente a sua divisão. Os ramos para o MS originaram-se do NIP. Identificamos, proximal à AF, 1 ramo para o MS em 6 membros (-Figs. 2A e 2B), 2 ramos para o supinador em 11 

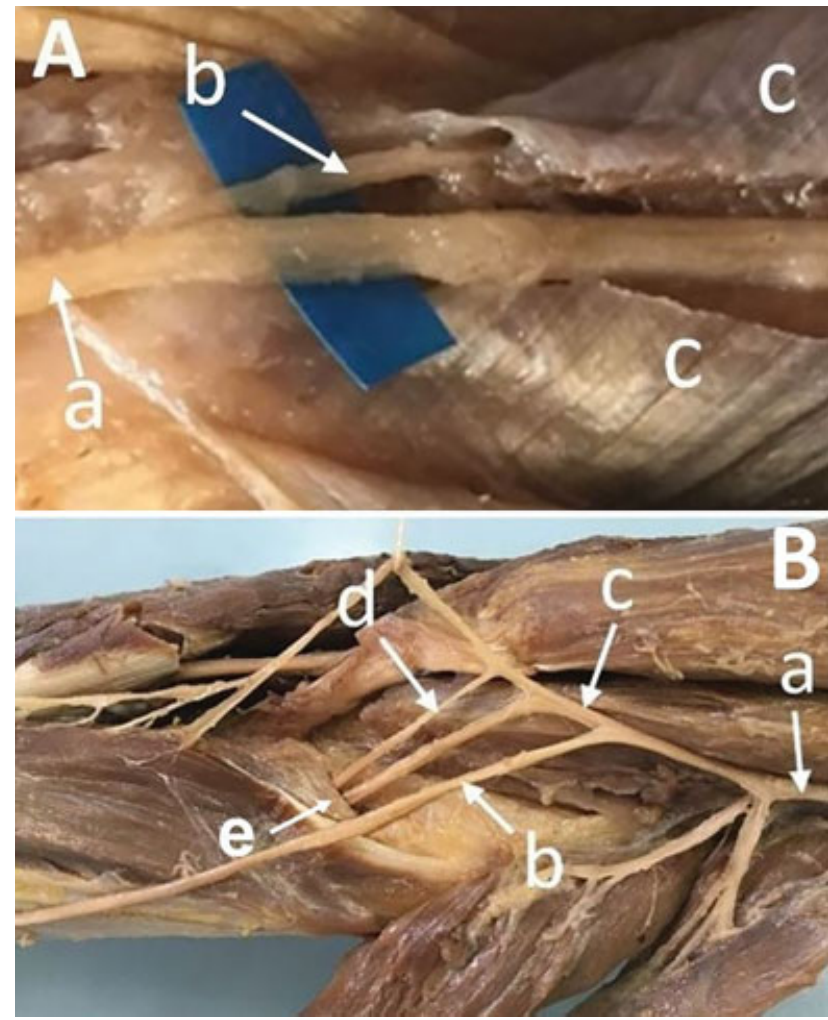

Fig. 2A Nervo interósseo posterior (a); um ramo para o supinador (b); músculo supinador seccionado (c); arcada de Frohse (d). 2B Nervo radial (a); ramo superficial do nervo radial (b); Nervo interósseo posterior (c); ramo para o supinador (d); arcada de (e).

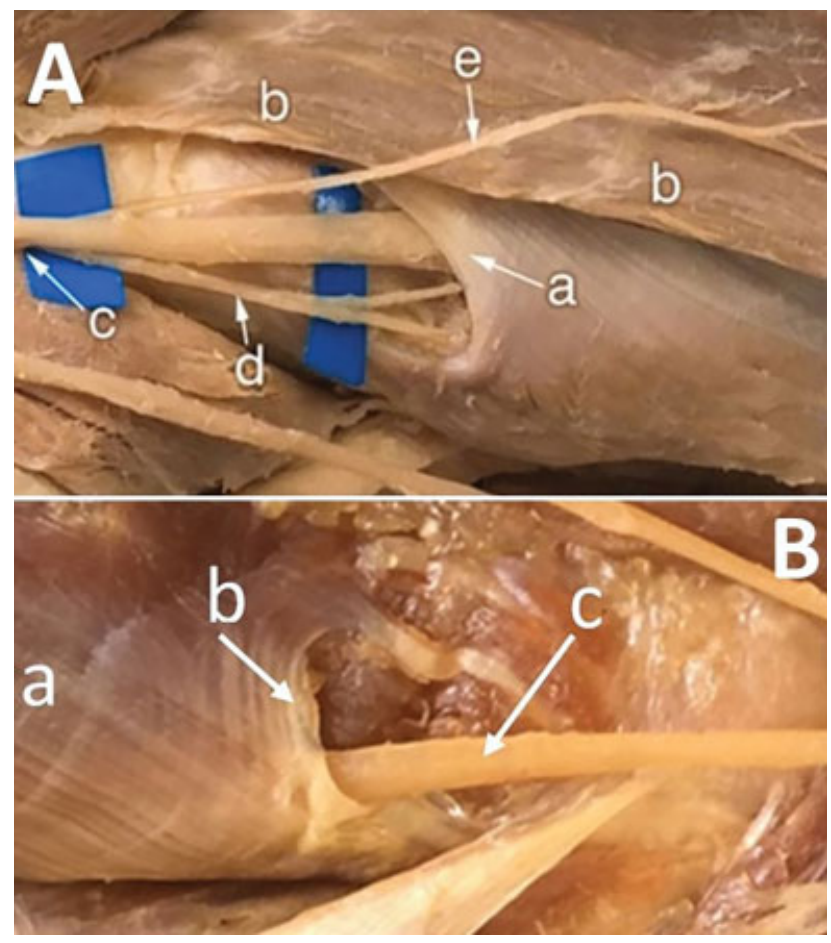

Fig. 4A Arcada de Frohse (a); Músculo extensor radial curto do carpo (b); Nervo interósseo posterior (c); Ramo para o supinador (d); Ramo para o músculo extensor radial curto do carpo (e) Cabeça superficial do músculo supinador 4B - músculo supinador (a); arcada de Frohse (b); Nervo interósseo posterior (c).
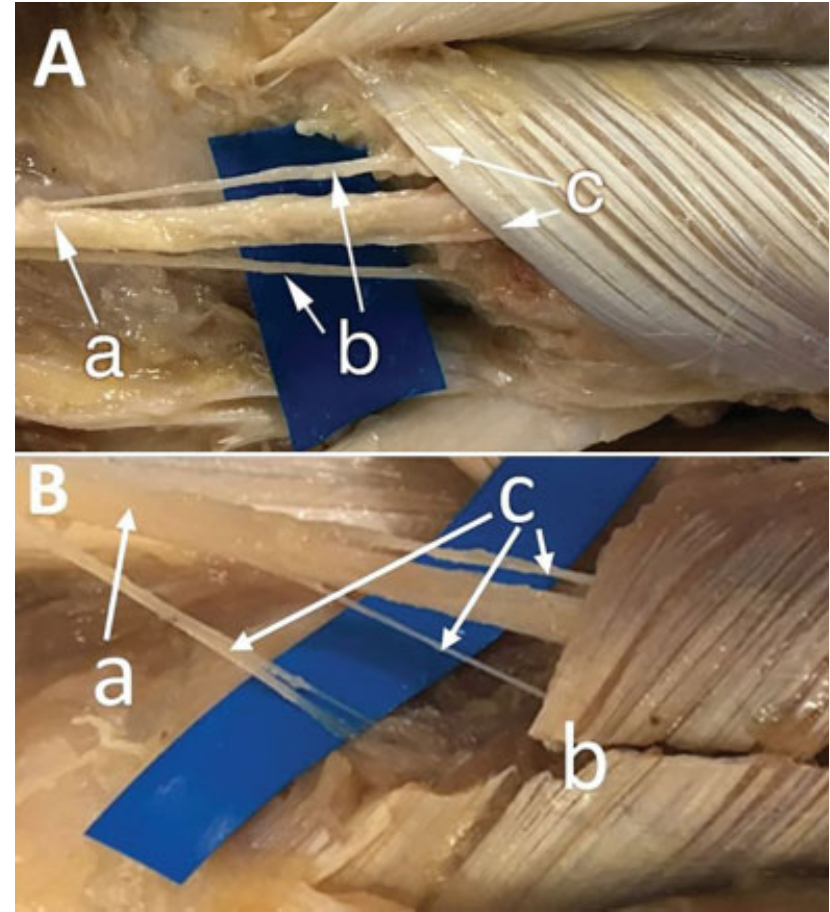

Fig. 3A Nervo interósseo posterior (a); dois ramos para o supinador (b); arcada de Frohse (c). 3B - Nervo interósseo posterior (a); Arcada de Frohse (b); Três ramos para o supinador (c).
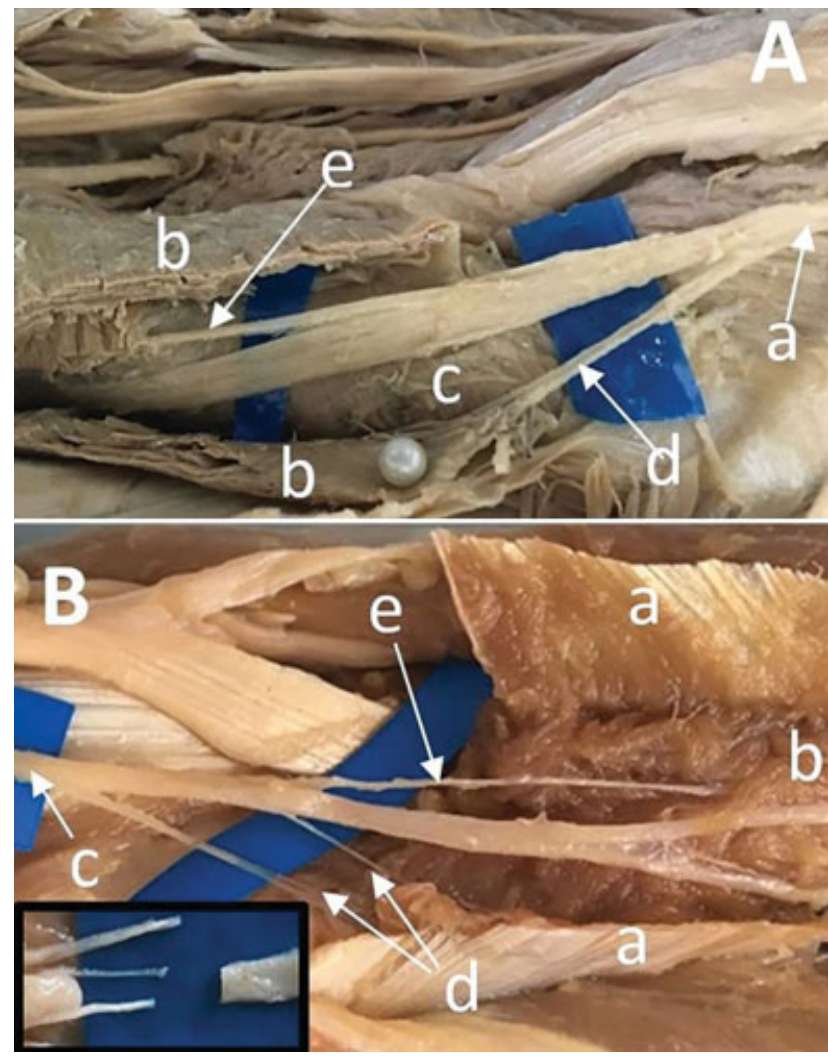

Fig. 5A NIA (a); Cabeça superficial (b); Cabeça profunda (c); Ramos para cabeça superficial (d); Ramo para a cabeça profunda (e); 5B Cabeça superficial (a); Cabeça profunda (b); Nervo interósseo posterior (c); Ramos para cabeça superficial (d); Ramo para a cabeça profunda (e). 

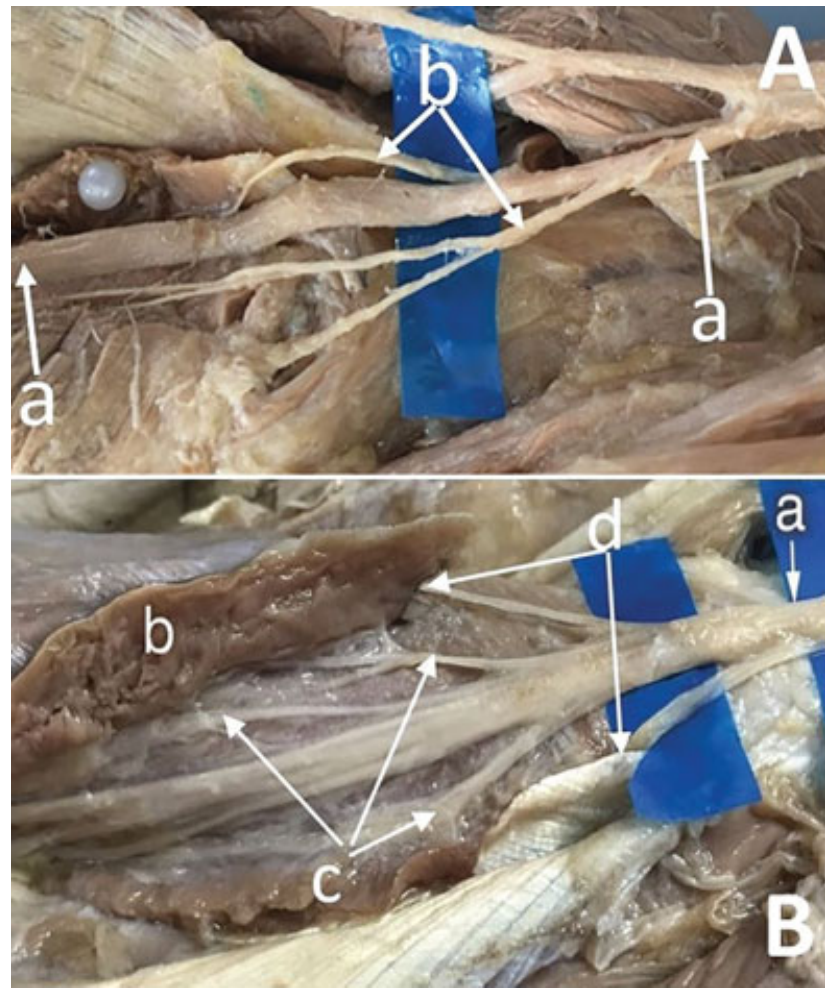

Fig. 6A Nervo interósseo posterior (a); Dois ramos para cabeça profunda (b); 6B - Nervo interósseo posterior (a); Músculo supinador (b); Três ramos para a cabeça profunda (c); Dois ramos para cabeça superficial (d).
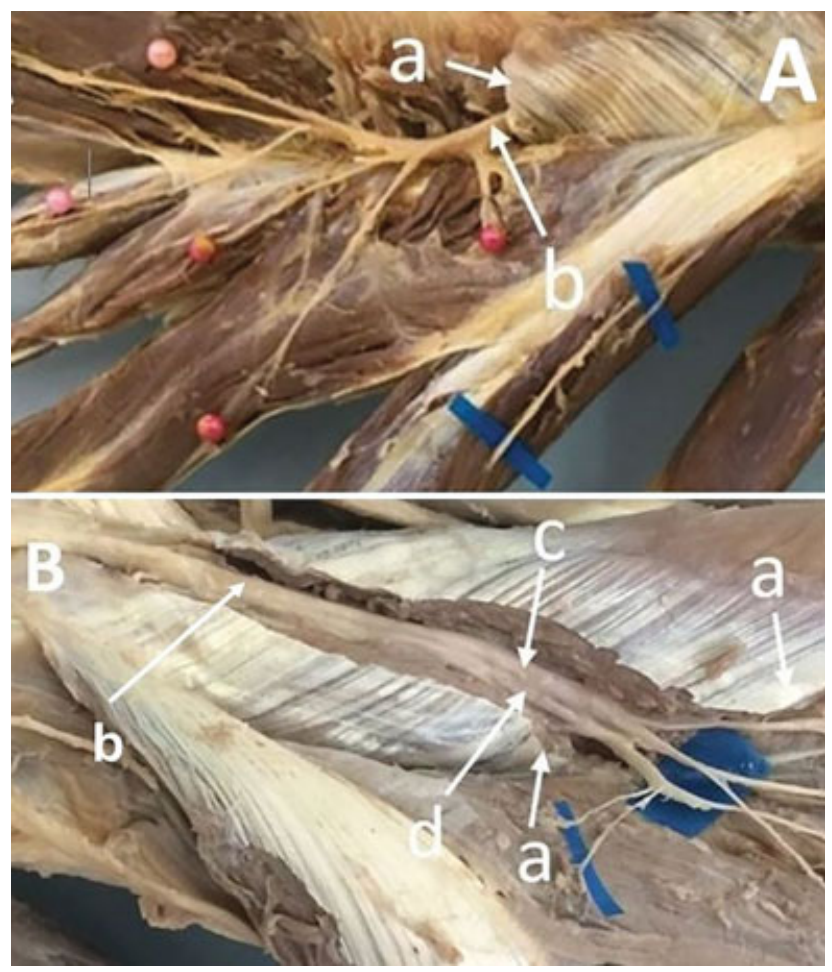

Fig. 8A Margem distal do supinador (a); Nervo interósseo posterior (b) ramificando distalmente a margem distal do supinador. 8B Margem distal do supinador (a); Nervo interósseo posterior(b); Ramo superficial do Nervo interósseo posterior (c) Ramo profundo do nervo interósseo posterior (d).

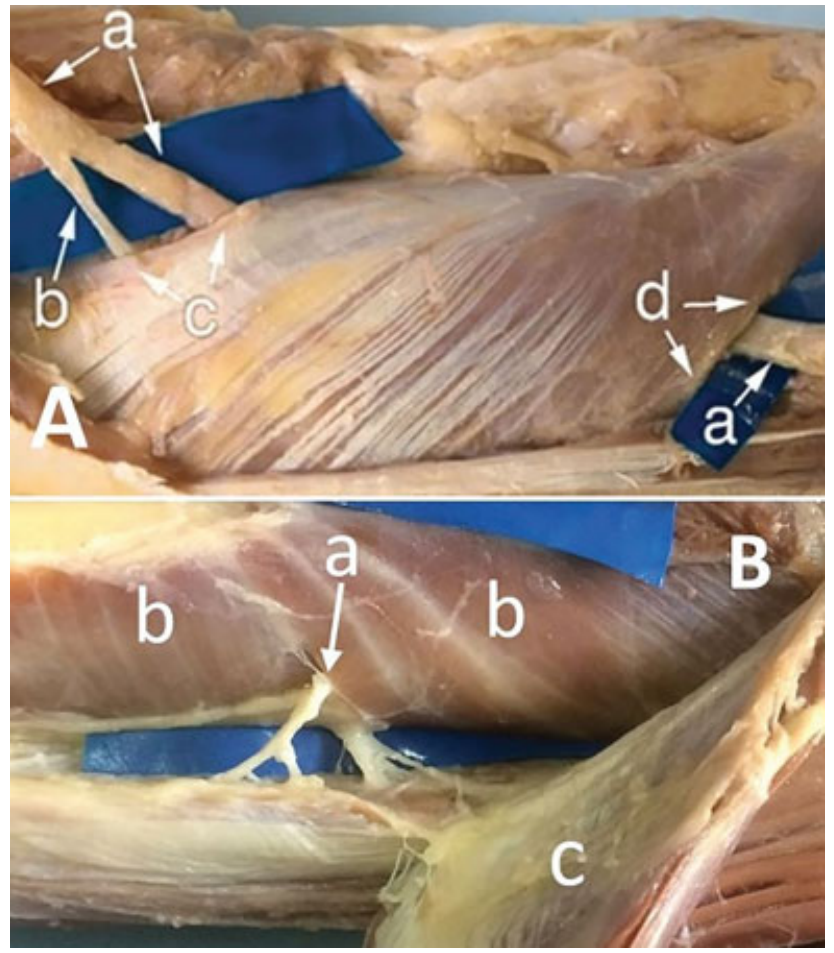

Fig. 7A Nervo interósseo posterior (a); Ramo para o supinador (b); Arcada de Frohse (c); Margem distal do supinador (d). 7B - Nervo interósseo posterior (a); Músculo supinador (b); Músculo extensor radial curto do carpo (c).
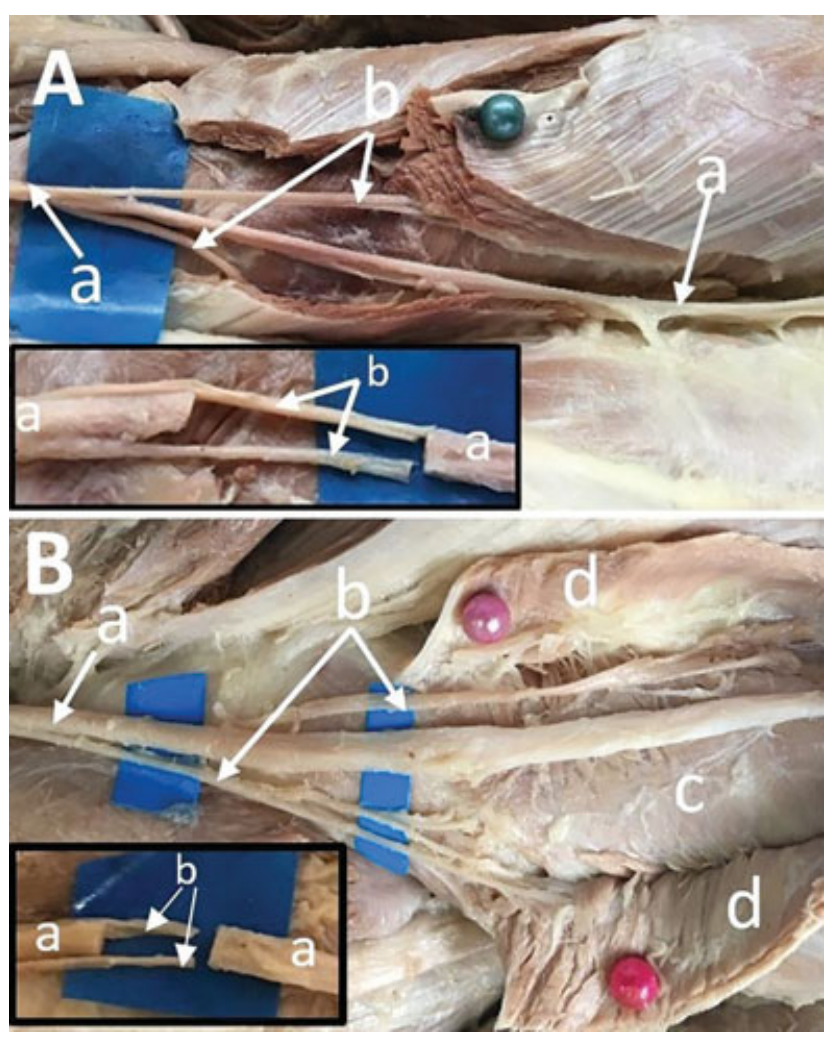

Fig. 9A Nervo interósseo posterior (a); Ramos para o supinador (b); No detalhe: simulação da neurotização. 9B - Nervo interósseo posterior (a); Ramos para o supinador (b); Cabeça profunda (c); Cabeça superficial (d); No detalhe: simulação da neurotização. 
membros (-Fig. 3A) e 3 ramos em 4 membros (-Fig. 3B). Em sete membros, não identificamos ramos para o MS proximal à $\mathrm{AF}$ ( - Fig. 4A). Outros autores ${ }^{1,5}$ também identificaram pelo menos dois ramos para o MS, um para a cabeça superficial outro para a cabeça profunda. Existe grande variabilidade na literatura em relação à constituição anatômica da AF. Spinner ${ }^{7}$ relata que estudou 25 membros de cadáveres adultos e 10 membros de fetos a termo. Informam que a ausência da AF fibrosa nos fetos, em contraste com a incidência de 30\% de arcada fibrosa em cadáveres de adultos, sugere que o componente fibroso da arcada se forma na parte proximal do MS em resposta ao movimento repetitivo de pronação e supinação do antebraço. Papadopoulos et al. ${ }^{16}$ analisaram uma série de 120 membros de cadáveres e observaram que a AF se apresentou fibrosa em 61 deles (51\%). Prasartritha et al. ${ }^{17}$ dissecaram 60 membros de 30 cadáveres, identificaram a $\mathrm{AF}$ de constituição membranosa em 26 (43\%) e fibro-tendinosa em 34 (57\%). Riffaud et al $^{18}$ dissecaram 25 membros de cadáveres e, em 23 (95\%) deles, identificaram a AF de constituição fibrosa. Ozturk et al $^{10}$ identificaram a AF tendinosa em 48 (87\%) dos membros de cadáveres adultos que estudaram. Clavert et $\mathrm{al}^{9}$ informam que AF tinha forma semicircular e se mostrou de consistência tendinosa em 26 membros (87\%) e de consistência membranosa nos 4 restantes (13\%). Identificamos a AF de conformação fibrosa em 22 membros (73\%) e muscular em 8 (27\%). As explicações pela discrepância dos números só podem ser explicadas pela diferente forma de interpretação da constituição da AF.

A supinação do antebraço é realizada por dois músculos, o bíceps braquial e o supinador, ambos músculos funcionais em paralisias C7-T1. ${ }^{14}$ Portanto, os sacrifícios dos ramos destinados ao músculo supinador não comprometem a supinação devido à compensação do bíceps. Além disso, em alguns casos, apenas um ramo foi usado para transferência, porque o outro ramo motor era muito fino. ${ }^{5}$ Nesses casos, o MS não foi completamente denervado, o que explica a supinação preservada, mesmo com o cotovelo totalmente estendido ou flexionado, abolindo assim a ação do bíceps. ${ }^{14}$

A transferência de ramos do nervo radial destinados ao MS para o NIP foi descrita para pacientes com lesões de raízes inferiores do plexo braquial com a finalidade de recuperar a extensão do punho e dos dedos. ${ }^{5,6}$ Bertelli et al. ${ }^{11}$ dissecaram 20 membros de cadáveres preparados em laboratório e registraram que o diâmetro médio do NIP distal ao ponto em que os ramos do MS se desprendiam dele foi $3,2 \pm 0,6 \mathrm{~mm}$, e o diâmetro médio dos ramos do MS foi 2,6 \pm 0,95 mm. Compararam o diâmetro do NIP e registraram que o diâmetro combinado dos ramos para o MS corresponde a cerca de $80 \%$ do NIP (2,6 versus 3,2 mm). Da mesma forma, o número de fibras mielinizadas nos ramos do MS foi de aproximadamente $70 \%$ do NIP distal à AF. Nós registramos resultados um pouco diferentes, o diâmetro médio dos ramos do MS foi de $1,6 \pm 0,5 \mathrm{~mm}$, e do NIP $3,0 \pm 0,7 \mathrm{~mm}$ assim, o diâmetro combinado dos ramos para o MS corresponde a cerca de 53,5\% do NIP. Em 12 membros essa relação foi inferior a 50\%, e em 3 inferior a 40\%. Essa diferença significativa entre os resultados dos estudos só pode ser explicada por diferentes formas de medições e interpretações.
Dong et al. ${ }^{5}$ relatam que, geralmente, existem dois ramos principais destinados ao MS, e o diâmetro do ramo maior tem aproximadamente metade do diâmetro do NIP. Em alguns casos, apenas um ramo foi usado para que o MS permanecesse com alguma inervação. Nossos achados estão de acordo que existem dois ou mais ramos para o MS, mas, em nossa medição, não identificamos algum ramo com diâmetro correspondente a 50\% do diâmetro do NIP. Isso não significa, em nossa opinião, que essa diferença de diâmetro entre os trabalhos possa interferir na eficácia dessa transferência nervosa.

Vários trabalhos descritos na literatura mostram que transferências nervosas de ramos com considerável diferença de diâmetro e de fibras nervosas proporcionam bons resultados. Por exemplo a transferência do ramo do nervo radial destinado à cabeça longa do tríceps braquial para o nervo axilar tem proporcionado bons resultados, mesmo que seu diâmetro seja inferior a $50 \%$ do diâmetro do nervo axilar. ${ }^{19}$ De Medinaceli et al. ${ }^{20}$ acreditam que a reinervação de 20 a 30\% das fibras musculares é compatível com a função muscular normal. Jiang et al. $^{21}$ informam que os axônios no coto proximal podem se multiplicar aumentando seu número de três a quatro vezes. Outros fatores reforçam a justificativa dessa transferência nervosa, mesmo que o diâmetro médio dos ramos do MS seja inferior a 50\% do diâmetro médio do NIP. Por exemplo, a força muscular necessária para a extensão dos dedos e do polegar é mínima, pois necessitamos de pouca força para abrir a mão, ou seja, a força muscular necessária para uma apreensão é maior do que o necessário para a liberação. ${ }^{11} \mathrm{~A}$ flexão do punho está preservada nas lesões C7 T1 e pelo efeito de tenodese a flexão do punho favorece a extensão dos dedos. ${ }^{2}$ Além disso, o MS é dispensável, não só porque sua função pode ser substituída pelo músculo do bíceps, mas também porque o supinador é um músculo intransferível devido à sua localização anatômica, o que proporciona um potencial ganho funcional sem sacrificar um músculo doador valioso para transferência de tendão. ${ }^{11}$

Sugerimos que a abordagem cirúrgica do NIP e da AF pode ser feita com o antebraço em pronação. A incisão deve ter aproximadamente $10 \mathrm{~cm}$ de comprimento, partindo do epicôndilo lateral acompanhando o eixo do rádio. Incisa-se a fáscia do antebraço e identifica-se o espaço entre o ERCC e o extensor comum dos dedos (ECD). A dissecção é aprofundada neste espaço, identificando-se a AF. O NIP, proximalmente à $\mathrm{AF}$, pode ser identificado pela palpação contra a diáfise do rádio. A cabeça superficial do MS deve ser seccionada, acompanhando o trajeto do NIP, expondo-se desta forma a porção intramuscular do NIP e os ramos destinados ao MS. A seguir, os ramos para o MS e o NIP devem ser seccionados, permitindo a conexão sem tensão.

Alguns autores relataram seus resultados clínicos com essa transferência nervosa. ${ }^{5,11,22-24}$ Dong et al. ${ }^{5}$ realizaram a transferência do ramo do motor do nervo radial destinado ao supinador para o NIP em quatro pacientes. Esses foram seguidos e avaliados a cada 3/4 meses pós-operatório. A extensão dos dedos foi recuperada entre 5 e 9 meses nos primeiros 3 casos e tiveram uma melhoria promissora ao longo do tempo. Os autores relatam ainda que um caso recente permanece sob acompanhamento e que eles 
concluíram que transferência do ramo do motor supinador para o NIP proporciona uma recuperação confiável da extensão dos dedos e do polegar, sendo, portanto, uma opção viável para paralisias de plexo braquial C7-T1. Em alguns casos, usaram apenas um ramo para o MS, pois o outro era muito fino. Bertelli e Ghizoni ${ }^{11}$ relatam os resultados clínicos da transferência dos ramos do nervo radial destinado ao MS para o NIP em quatro pacientes com lesão das raízes C7-T1, os quais foram submetidos a cirurgia entre 5 e 7 meses após a lesão. Os pacientes foram avaliados 12 meses após a cirurgia. A extensão dos dedos e do polegar foi restaurada em todos os pacientes. Xu et al. ${ }^{25}$ relataram que nos casos de paralisia do plexo braquial C7-T1, não havia um método confiável para a reconstrução da extensão dos dedos e do polegar até que a transferência do ramo do motor supinador para o NIP fosse proposta. Realizaram essa transferência nervosa em 10 pacientes, 9 recuperaram pelo menos a força muscular M3 (amplitude de movimento completa vencendo a gravidade e pequena resistência). Zhang et al. ${ }^{22}$ realizaram a transferência de um dos ramos do MS para o NIP em dois pacientes. Informam que este procedimento provou ser confiável, eficaz e rápido na restauração da extensão dos dedos e do polegar. Foi eficiente mesmo em um caso tardio em que o intervalo entre trauma e cirurgia excedeu 15 meses, devido à curta distância de regeneração entre o nervo doador e receptor. Os pacientes não só recuperaram a extensão dos dedos e do polegar, mas também tinham recuperação M3 do músculo extensor ulnar do carpo. Van Zyl et al. ${ }^{23}$ apresentaram o caso de um homem de 21 anos com tetraplegia em nível C6. Realizaram uma transferência tripla dos nervos. Um ramo nervoso destinado ao músculo redondo menor foi transferido para a ramo da cabeça longa do tríceps braquial, o ramo do nervo musculocutâneo destinado ao músculo braquial para o nervo interósseo anterior e o ramo do nervo supinador foi transferido para o NIP. Resultaram em sucesso para reconstruir a extensão do cotovelo, pinça digital, e a preensão e liberação de objetos. Bertelli et al. ${ }^{1}$ relatam que realizaram cirurgias para restaurar a flexão do cotovelo e dos dedos em 13 membros superiores de 7 pacientes com tetraplegia, com idade média de 26 anos. Os pacientes foram operados em média 7 meses após a lesão medular. A extensão do cotovelo foi restaurada pela transferência de ramos do nervo axilar para a cabeça longa do tríceps braquial. A extensão dos dedos e do polegar pela transferência de ramos do MS para o NIP. Observou-se que 12 pacientes recuperaram a extensão dos dedos e do polegar com capacidade de vencer a gravidade e certa resistência que significa uma excelente recuperação. Li et al. ${ }^{24}$ relatam que em três dos pacientes que operaram houve a recuperação da extensão M4 (amplitude de movimento completa vencendo a gravidade e uma resistência moderada) do polegar e a extensão dos dedos após a transferência nervosa de ramos do MS para o NIP.

\section{Conclusões}

Este estudo anatômico mostra que ramos do nervo radial destinados ao MS podem ser transferidos diretamente para o
NIP, sem tensão, com a finalidade de restaurar a extensão do polegar e dos dedos em pacientes com lesões das raízes C7C8 e T1 do plexo braquial. O diâmetro somado dos ramos destinados ao MS correspondeu em média a 53,5\% do diâmetro do NIP.

\section{Conflito de Interesse}

Os autores declaram que não houve conflito de interesse.

\section{Referencias}

1 Bertelli JA, Ghizoni MF. Nerve transfers for elbow and finger extension reconstruction in midcervical spinal cord injuries. J Neurosurg 2015;122(01):121-127

2 Mackinnon SE, Yee A, Ray WZ. Nerve transfers for the restoration of hand function after spinal cord injury. J Neurosurg 2012;117 (01):176-185

3 García-López A, Fernández E, Martínez F. Transfer of brachioradialis motor branch to the anterior interosseous nerve in C8-T1 brachial plexus palsy. An anatomic study. Microsurgery 2013;33 (04):297-300

4 Garg R, Merrell GA, Hillstrom HJ, Wolfe SW. Comparison of nerve transfers and nerve grafting for traumatic upper plexus palsy: a systematic review and analysis. J Bone Joint Surg Am 2011;93 (09):819-829

5 Dong Z, Gu YD, Zhang CG, Zhang L. Clinical use of supinator motor branch transfer to the posterior interosseous nerve in C7-T1 brachial plexus palsies. J Neurosurg 2010;113(01):113-117

6 Vergara-Amador E, Ramírez A. Anatomic study of the extensor carpi radialis brevis in its relation with the motor branch of the radial nerve. Orthop Traumatol Surg Res 2015;101(08):909-912

7 Spinner M. The arcade of Frohse and its relationship to posterior interosseous nerve paralysis. J Bone Joint Surg $\mathrm{Br}$ 1968;50(04): 809-812

8 Frohse F, Fränkel M. Die muskeln des menschlichen armes. In: Bardeleben K, ed. Handbuch der anatomie des menschen. Jena: von Gustav Fischer; 1908

9 Clavert P, Lutz JC, Adam P, Wolfram-Gabel R, Liverneaux P, Kahn JL. Frohse's arcade is not the exclusive compression site of the radial nerve in its tunnel. Orthop Traumatol Surg Res 2009;95(02): $114-118$

10 Ozturk A, Kutlu C, Taskara N, Kale AC, Bayraktar B, Cecen A. Anatomic and morphometric study of the arcade of Frohse in cadavers. Surg Radiol Anat 2005;27(03):171-175

11 Bertelli JA, Ghizoni MF. Transfer of supinator motor branches to the posterior interosseous nerve in C7-T1 brachial plexus palsy. J Neurosurg 2010;113(01):129-132

12 Roberts MM, Oliveros P. Electrodiagnostic examination of the supinator-a more dorsal approach: a brief report. Am J Phys Med Rehabil 1999;78(03):281-282

13 Russel SM. Examination of the peripheral nerve injuries: an anatomical approach. New York: Thieme; 2006:91-92

14 Tubiana R, Thomine JM, Mackin E. Examination of the hand and wrist. London: Martin Dunitz; 1996:286-327

15 Ray WZ, Yarbrough CK, Yee A, Mackinnon SE. Clinical outcomes following brachialis to anterior interosseous nerve transfers. J Neurosurg 2012;117(03):604-609

16 Papadopoulos N, Paraschos A, Pelekis P. Anatomical observations on the arcade of Frohse and other structures related to the deep radial nerve. Anatomical interpretation of deep radial nerve entrapment neuropathy. Folia Morphol (Praha) 1989;37(03): 319-327

17 Prasartritha T, Liupolvanish P, Rojanakit A. A study of the posterior interosseous nerve (PIN) and the radial tunnel in 30 Thai cadavers. J Hand Surg Am 1993;18(01):107-112

18 Riffaud L, Morandi X, Godey B, Brassier G, Guegan Y, Darnault P, et al. Anatomic bases for the compression and neurolysis of the 
deep branch of the radial nerve in the radial tunnel. Surg Radiol Anat 1999;21(04):229-233

19 Witoonchart K, Leechavengvongs S, Uerpairojkit C, Thuvasethakul P, Wongnopsuwan V. Nerve transfer to deltoid muscle using the nerve to the long head of the triceps, part I: an anatomic feasibility study. J Hand Surg Am 2003;28(04):628-632

20 de Medinaceli L, Rawlings RR. Is it possible to predict the outcome of peripheral nerve injuries? A probability model based on prospects for regenerating neurites. Biosystems 1987;20(03): 243-258

21 Jiang BG, Yin XF, Zhang DY, Fu ZG, Zhang HB. Maximum number of collaterals developed by one axon during peripheral nerve regeneration and the influence of that number on reinnervation effects. Eur Neurol 2007;58(01):12-20
22 Zhang CG, Dong Z, Gu YD. Restoration of hand function in C7-T1 brachial plexus palsies using a staged approach with nerve and tendon transfer. J Neurosurg 2014;121(05):1264-1270

23 van Zyl N, Hahn JB, Cooper CA, Weymouth MD, Flood SJ, Galea MP. Upper limb reinnervation in C6 tetraplegia using a triple nerve transfer: case report. J Hand Surg Am 2014;39(09): 1779-1783

24 Li Z, Reynolds M, Satteson E, Nazir O, Petit J, Smith BP. Double distal intraneural fascicular nerve transfers for lower brachial plexus injuries. J Hand Surg Am 2016;41(04):e15-e19

25 Xu B, Dong Z, Zhang CG, Gu YD. Clinical outcome following transfer of the supinator motor branch to the posterior interosseous nerve in patients with C7-T1 brachial plexus palsy.J Reconstr Microsurg 2015;31(02):102-106 